\title{
Malnutrition management of hospitalized patients with diabetes/ hyperglycemia and COVID-19 infection
}

\author{
Rosa Burgos ${ }^{1}$. José Manuel García-Almeida ${ }^{2}$ Pilar Matía-Martín ${ }^{3} \cdot$ Samara Palma ${ }^{4}$ - Alejandro Sanz-Paris ${ }^{5,6}$ (i) . \\ Ana Zugasti $^{7}$ - José Joaquín Alfaro ${ }^{8}$ - Ana Artero Fullana ${ }^{9}$. Alfonso Calañas Continente ${ }^{10}$ - María Jesús Chicetru ${ }^{11}$. \\ Katherine García Malpartida ${ }^{12}$. Ángela González Faes ${ }^{13}$. Víctor González Sánchez ${ }^{14}$. María Lainez López ${ }^{15}$. \\ Antonio Jesús Martínez Ortega ${ }^{16}$. Juana Oliva Roldán ${ }^{17}$. Clara Serrano Moreno ${ }^{18}$. Pablo Suárez Llanos ${ }^{19}$
}

Accepted: 27 January 2022 / Published online: 4 March 2022

(c) The Author(s) 2022

\begin{abstract}
Diabetes mellitus and/or hyperglycemia are highly prevalent medical conditions in patients hospitalized for coronavirus disease 2019 (COVID-19) and are associated with adverse outcomes. In addition, COVID-19 itself can provoke fluctuating and high glucose levels that can be difficult to manage upon hospitalization. Hospitalized patients with COVID-19 are at high risk of malnutrition due to an increase in nutritional requirements and a severe acute inflammatory response. The management of patients with diabetes/hyperglycemia and COVID-19 is challenging and requires a specific nutritional approach, the purpose of which is to fulfill the nutritional requirements while maintaining an optimal glycemic control. In this study, an expert group of nutritional endocrinologists carried out a qualitative literature review and provided recommendations based on evidence and guidelines, when available, or on their own experience. The optimal care based on these recommendations was compared with the routine bedside care as reported by a panel of physicians (mainly, endocrinologists, geriatricians, and internists) treating patients with diabetes/hyperglycemia and COVID-19 in their daily practice. Early screening and diagnosis, a diabetesspecific therapeutic approach, and a close malnutrition monitoring are essential to improve the clinical outcomes of these patients. In conclusion, the proposed recommendations are intended to provide a useful guide on the clinical management of malnutrition in patients with COVID-19 and diabetes/hyperglycemia, in order to improve their outcomes and accelerate their recovery. The comparison of the recommended optimal care with routine clinical practice could aid to identify gaps in knowledge, implementation difficulties, and areas for improvement in the management of malnutrition in this population.
\end{abstract}

Keywords COVID-19 $\cdot$ Diabetes $\cdot$ Hyperglycemia $\cdot$ Malnutrition $\cdot$ Medical nutrition

Alejandro Sanz-Paris

asanzp@salud.aragon.es

1 Unidad de Soporte Nutricional, Hospital Universitari Vall d'Hebron, Barcelona, Spain

2 Unidad de Gestión Clínica de Endocrinología Y Nutrición, Hospital Virgen de La Victoria, Málaga, Spain

3 Departamento de Endocrinología Y Nutrición, Hospital Clínico San Carlos, Madrid, Spain

4 Unidad de Nutrición Clínica Y Dietética, Hospital Universitario de La Paz, Madrid, Spain

5 Nutrition Department, Miguel Servet University Hospital, 50009 Zaragoza, Spain

6 Instituto de Investigación Sanitaria (IIS) Aragón, 50009 Zaragoza, Spain

7 Unidad de Nutrición Clínica, Hospital Universitario de Navarra, 31008 Pamplona, Spain
8 Complejo Hospitalario Universitario de Albacete, Albacete, Spain

9 Hospital Universitario General, Valencia, Spain

10 Hospital Universitario Reina Sofía, Córdoba, Spain

11 Hospital San Pedro, La Rioja, Spain

12 Hospital Universitario Politécnico La Fé, Valencia, Spain

13 Hospital de Marqués de Valdecilla, Santander, Spain

14 Hospital de Alcorcón, Madrid, Spain

15 Hospital Juan Ramon Jimenez, Huelva, Spain

16 Hospital Universitario Torrecardenas, Huelva, Spain

17 Hospital Universitario Infanta Sofía, Madrid, Spain

18 Hospital Universitario Gregorio Marañón, Madrid, Spain

19 Hospital Nuestra Señora de La Candelaria, Tenerife, Spain 


\section{Introduction}

The coronavirus disease 2019 (COVID-19), declared a global pandemic by the World Health Organization in March 2020 , is caused by the severe acute respiratory syndrome coronavirus 2 (SARS-CoV-2), and has provoked an excess morbidity and mortality and a great public health burden worldwide [1,2]. The clinical manifestations of COVID-19 are unspecific and similar to many other diseases of viral etiology. The most frequent symptoms are fever, cough, headache, fatigue, anorexia, and myalgias [3, 4], while anosmia and dysgeusia are somewhat less frequent but more specific, although not exclusive, of COVID-19 [5]. In patients requiring hospitalization, COVID-19 is characterized by dyspnea, hypoxemia, and bilateral pneumonia, which can lead to severe respiratory failure requiring admission to intensive care units (ICU) [6, 7]. In these cases, organ dysfunctions are common, mainly due to lung and cardiovascular injury. Recently, a direct injury on insulin-secreting $\beta$ cells in the pancreas has been described [8].

Together with hypertension, diabetes mellitus and/or hyperglycemia are highly prevalent medical conditions in patients hospitalized for COVID-19 [6, 9] and have demonstrated to be poor prognostic factors, increasing the probabilities of ICU admission and mortality [10, 11]. People with diabetes experiment several pathophysiological changes that could make them prone to a more severe COVID-19, including chronic inflammation, increased coagulation activity, compromised immune response, endothelial dysfunction, and potential pancreatic damage by SARS-CoV-2 [12, 13], whereas sustained hyperglycemia has been associated with persistently elevated interleucin-6 and D-dimer levels during hospitalization [14]. Furthermore, the COVID-19 itself can provoke fluctuating and high glucose levels that can be difficult to manage upon hospitalization and are associated with worse outcomes [15].

Chronic and acute infections negatively impact on nutritional state. Disease-related malnutrition (DRM) is a condition to fight in any disease that requires hospital admission, since it is a poor prognostic factor $[16,17]$. Hospitalized patients with COVID-19 are at high risk of DRM due to an increase in nutritional requirements and the severe acute inflammatory response that they usually develop $[18,19]$. In addition, various COVID-19 symptoms can compromise a sufficient intake, such as anorexia, dyspnea, asthenia, ageusia/anosmia, cough and dysphagia, whereas digestive symptoms (bloating or abdominal pain, diarrhea) entail abnormal absorption of nutrients [20]. Thus, the management of these patients is challenging and requires a specific nutritional approach, the purpose of which is to fulfill the nutritional requirements while maintaining an optimal glycemic control [21]. The objectives of this study were to generate, based on the available data and clinical experience, consensus recommendations by a group of Spanish experts for the clinical management of malnutrition in hospitalized patients with COVID-19 and diabetes/hyperglycemia, and to compare the optimal care based on these recommendations with the routine bedside care as reported by a panel of Spanish physicians in their daily practice.

\section{Methods}

\subsection{Expert group-based consensus recommendations}

The scientific committee consisted of 6 coordinators and 12 clinical experts, all selected according to the following criteria: members of the Spanish Society of Endocrinology and Nutrition and/or Chief of their hospitals' Endocrinology and Nutrition Departments, with more than 10 years of experience in ground and treating hospitalized patients with COVID-19. The 6 coordinators conducted a comprehensive literature search on Pubmed/Medline to identify relevant articles and clinical guidelines. The keywords that were used included malnutrition, diabetes, hyperglycemia, SARSCoV-2, and COVID-19 (bibliographic search performed in October 2020, updated in October 2021). After reviewing the evidence, they elaborated a questionnaire with various statements and questions about the management of patients with COVID-19 and diabetes/hyperglycemia, grouped into 5 topics: (1) Risk factors for and screening of malnutrition; (2) Assessment and diagnosis of malnutrition; (3) Energy and nutrient requirements; (4) Enteral nutritional care plan (oral and feeding tube); (5) Malnutrition reevaluation and monitoring.

The scientific committee answered remotely the questionnaire and rated their agreement with each statement on a 5-point Likert scale (1-strongly disagree, 5-strongly agree) [22]. A cut-off of $80 \%$ or more agreement among them determined consensus. Those questions that did not obtain the stablished degree of agreement were discussed in a virtual meeting to try to understand the reasons of no consensus and/or try to reach consensus. The experts then generated the recommendations for nutritional management of hospitalized COVID-19 patients with diabetes/hyperglycemia, which were considered the optimal care.

\subsection{Daily practice reported by the panel of physicians}

A selected sample of 90 physicians with more than 5 years of experience and treating COVID-19 patients were sent the questionnaire elaborated by the coordinators to gather their opinions and usual practice regarding each of the topics 
addressed in the consensus recommendations. The agreement with each statement was again rated by the Likert scale [22], and they were allowed to explain the reasons of agreement or disagreement as free-text comments. The responses of the panel of physicians ("panelists") were compared with the clinical management recommended by the experts. To facilitate the comparison, each recommendation is described together with the corresponding clinical practice reported by the panelists in tabular format.

\section{Results}

The most frequent medical specialty among the 90 panelists was Endocrinology (72.2\%), followed by Geriatrics (12.2\%) and Internal Medicine (10.0\%).

\subsection{Risk factors for and screening of malnutrition}

The questionnaire began with a series of questions about the characteristics of patients with diabetes/hyperglycemia and COVID-19 and the associated risk factors for adverse outcomes. As reflected by the answers of the panelists, most of them (87.8\%) agreed that diabetes mellitus is one of the most common comorbidities in COVID-19 patients; according to their experience, the presence of hyperglycemia is a poor prognosis factor for these patients. Hospitalized diabetic patients with COVID-19 are often at risk of malnutrition, and they estimated that nearly $50 \%$ of the patients cared by them had malnutrition. All were aware that obesity in patients with diabetes/hyperglycemia could mask the risk of malnutrition, and they agreed that patients admitted for SARS-CoV-2 infection are at high risk of malnutrition; 95\% of respondents believed that dyspnea and anorexia are symptoms that can increase the risk of malnutrition by compromising a sufficient intake, whereas $87 \%$ indicated diarrhea as a symptom that could increase the risk of malnutrition, due to poor nutrient absorption.

Table 1 shows the consensus recommendations reached by the scientific committee related to the risk factors for and screening of malnutrition, and the responses of the panelists for each statement. Panelists' answers indicated that only 1 out 3 used a severity scale in patients with COVID-19, being the CURB-65 severity scale [23] the most common. For nutritional screening, the Malnutrition Universal Screening Tool (MUST) [24] was the preferred both by the experts and the panelists. The nutritional assessment should be based on diet survey, analytical parameters, and anthropometrics,

Table 1 Comparative of the optimal care according to the experts' recommendations and the usual clinical practice of the panelists regarding risk factors for and screening of malnutrition

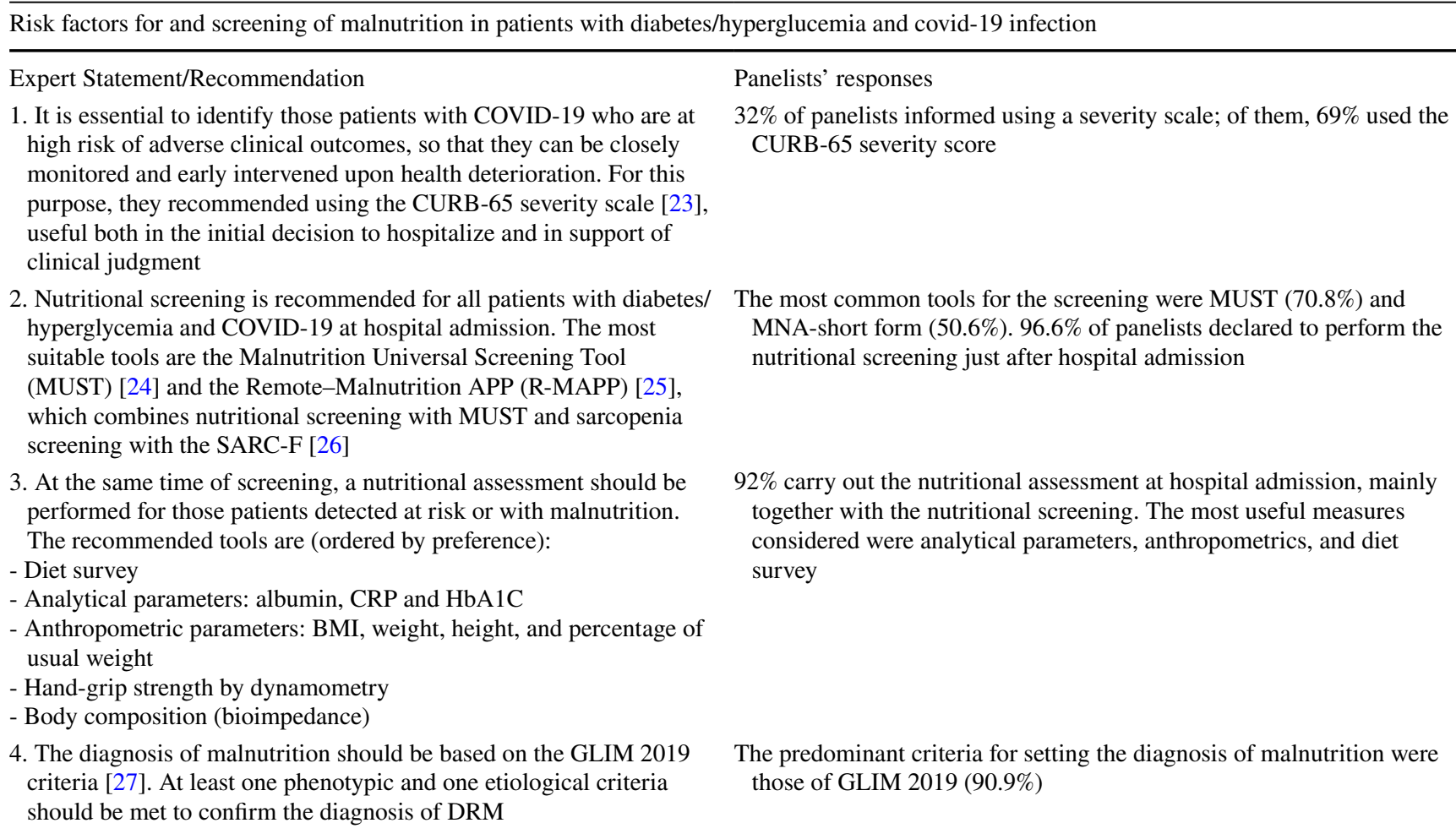

CRP C-reactive protein, GLIM Global Leadership Initiative on Malnutrition, MNA Mini Nutritional Assessment, SARC-F Strength, assistance with walking, rising from a chair, climbing stairs, and falls questionnaire 
although other measures are also useful. GLIM 2019 criteria [27] for diagnosis of malnutrition were recommended and the predominantly used.

\subsection{Energy and nutrient requirements}

As showed in Table 2, the calculation of energy expenditure and establishing energy and protein requirements in patients without renal failure had a high degree of agreement. For patients with renal failure, protein needs were more controverted. The panelists reported that the most important diet components among the recommended by the experts were proteins of high biological value, low glycemic index and slow absorption carbohydrates; polyunsaturated fatty acids with anti-inflammatory properties, and specific amino acids (leu) or their metabolites ( $\beta$-hydroxy- $\beta$-methylbutyrate).

\subsection{Enteral nutritional care plan}

A specific diabetes diet for patients with diabetes/hyperglycemia and COVID-19 seems mandatory. The experts recommended the glycemic goals established by the American Diabetes Association; however, the panelists mostly preferred a fasting glycemia below $140 \mathrm{mg} / \mathrm{dL}$ The postprandial glucose below $180 \mathrm{mg} / \mathrm{dL}$ had a higher level of agreement (Table 3). There was a general agreement on the adequacy of supplementing with a diabetes-specific polymeric, hypercaloric and high-protein formula for patients with diabetes/hyperglycemia and COVID-19, as this formula can achieve an adequate glycemic control. When oral intake is impaired, the best option is a nasogastric tube (NGT) for enteral feeding. Agreeing with the experts' recommendation, most of the panelists opined that in case of risk of aspiration or limited gastric tolerance despite treatment with prokinetic drugs, a nasojejunal tube (NJT) may be placed for enteral nutrition. For prolonged tube enteral nutrition ( $>4$ weeks), gastrostomy was considered as an adequate route of administration (Table 3). Half of the panelists used formulas for tube feeding with the same characteristics as the oral nutrition supplements, and the other half of them used specific formulas for enteral tube feeding. The speed of feeding should be progressive to facilitate tolerance.

\subsection{Malnutrition reevaluation and monitoring}

Before hospital discharge, it is recommended to carry out a new nutritional assessment; if the patient has any degree of malnutrition, the nutritional supplementation regimen with hypercaloric and high-protein formulas specific for diabetes/ hyperglycemia should be maintained. The panelists opined that the frequency of follow-up visits should depend on the nutritional status of each patient. During the follow up, the most important goal reported by the panelists was to avoid marked fluctuations in blood glucose. Table 4 shows the consensus recommendations reached by the scientific committee related to malnutrition reevaluation and monitoring, and the responses of the panelists for each statement.

Table 2 Comparative of the optimal care according to the experts' recommendations and the usual clinical practice of the panelists regarding energy and nutrient requirements

Energy and nutrient requirements in patients with diabetes/hyperglucemia and covid-19 infection

Expert Statement/Recommendation

5. To calculate the specific energy expenditure of patients, it is recommended to use estimation formulas according to body weight. When BMI $>30 \mathrm{~kg} / \mathrm{m}^{2}$, the adjusted body weight (BW) should be used (Adjusted BW = Ideal BW +0.25 x [actual BW - ideal BW]) [27]

6 . The energy requirements of hospitalized COVID-19 patients with diabetes/hyperglycemia are $25-30 \mathrm{kcal} / \mathrm{kg}$ body weight/day and protein requirements are $1.2 \mathrm{~g} / \mathrm{kg}$ body weight/day. For those patients with renal failure, protein needs range from $0.8 \mathrm{~g} / \mathrm{kg}$ body weight $/$ day in pre-dialysis to $1.2-1.5 \mathrm{~g} / \mathrm{kg}$ body weight/day in renal replacement therapy

7: The following components should be included for intake:

- Proteins of high biological value (casein, whey, soy)

- Specific amino acids (leu) or their metabolites ( $\beta$-hydroxy- $\beta$ methylbutyrate)

- Fats: monounsaturated fatty acids, polyunsaturated fatty acids with anti-inflammatory properties (EPA, DHA)

- Fiber (fructooligosaccharides)

- Low glycemic index and slow absorption carbohydrates (maltodextrins)

- Liquids

- Vitamins and trace elements (calcium, vitamin D)
Panelists' responses

$86.4 \%$ agreed with the recommendation

$73 \%$ of panelists stated their agreement with the caloric provision of $25-30 \mathrm{kcal} / \mathrm{kg}$ body weight/day, whereas $90 \%$ indicated that the protein requirements that they use are $1.2-2.4 \mathrm{~g} / \mathrm{kg}$ body weight/ day. For pre-dialysis and renal replacement therapy, the protein requirements were set in $0.8 \mathrm{~g} / \mathrm{kg}$ body weight/day (54.4\%) and $1.2-1.5 \mathrm{~g} / \mathrm{kg}$ body weight/day ( $\sim 55 \%)$ respectively

Percentages of agreement:

$94.4 \%$ for proteins of high biological value;

$83.3 \%$ for specific amino acids

$87.8 \%$ for polyunsaturated fatty acids with anti-inflammatory properties;

$78.9 \%$ for fiber

$90.0 \%$ for low glycemic index and slow absorption carbohydrates;

$68.9 \%$ for liquids;

$78.9 \%$ for vitamins and trace elements

DHA Docosahexaenoic acid, EPA Eicosapentaenoic acid 
Table 3 Comparative of the optimal care according to the experts' recommendations and the usual clinical practice of the panelists regarding the enteral nutritional care plan

Enteral nutritional care plan in patients with diabetes/hyperglucemia and covid-19 infection

Expert Statement/Recommendation

8. Oral feeding is the main choice for all patients, as long as the nutritional requirements are met. A specific diabetes diet is recommended from admission, with aliments easy to ingest and good flavored, adapted in texture for those patients who need it, and adapted in fiber if there are gastrointestinal symptoms. Glycemic goals and monitoring in these patients will be based on those recommended by the American Diabetes Association [28]:

- Glycemic goal: 140-180 mg/dL (may be 110-140 mg/dL in selected patients)

- Postprandial glucose: $<180 \mathrm{mg} / \mathrm{dL}$

Continuous glucose monitoring (CGM) is advisable to minimize contact between health care providers and patients, especially those in the intensive care unit

9. Depending on the intake and the nutritional assessment during hospitalization, patients' diets should be supplemented with a diabetes-specific polymeric, hypercaloric and high-protein formula, since these products achieve adequate glycemic control. In the event that the patient cannot ingest $50 \%$ of the hospital diet or nutritional supplementation for more than $24 \mathrm{~h}$, it is recommended to start enteral nutritional support

10. In case of impeded oral intake, the nasogastric tube (NGT) is the enteral route of choice, provided that there is no added risk of aspiration (i.e., diabetic gastroparesis) or limited gastric tolerance despite treatment with prokinetic drugs. In these cases, a nasojejunal tube (NJT) will be placed for enteral nutrition. If prolonged tube enteral nutrition ( $>4$ weeks) is expected and the patient no longer has active SARS-CoV-2 infection (negative PCR), gastrostomy should be considered as an indicated route of administration

11. The formulas for tube enteral nutrition should have the same characteristics as oral nutrition supplements. It is advisable to facilitate tolerance to tube-based feeding by starting with low-dose feeds; volumes of the feeds should be increased in case of good tolerance until reaching the total requirements. Peristaltic pump infusion can improve tolerance versus gravity-fed infusion

12. For $1 \mathrm{st}-2^{\text {nd }}$ day of enteral feeding, start feed at $20 \mathrm{~mL} / \mathrm{h}$ to test tolerance, and increase the speed every $6 \mathrm{~h}$ to try to achieve $50 \%$ of patients' nutritional requirements in the first $24-48 \mathrm{~h}$. At days 3 to 7 , increase progressively, assessing digestive tolerance, to $20-25 \mathrm{kcal} /$ $\mathrm{kg} / \mathrm{day}$. From day 7 , escalate to $30 \mathrm{kcal} / \mathrm{kg} /$ day

\section{Panelists' responses}

$71 \%$ of panelists always establish a specific diet for patients with diabetes/hyperglycemia and COVID-19 just after admission. Among the participants who established a specific diet, $71 \%$ considered that the diet adaptation should be based on enriched aliments, and $69 \%$ that it should be texture-modified

The most fasting glycemic goal selected by the panelists was $<140 \mathrm{mg}$ / $\mathrm{dL}(41.1 \%)$, whereas for postprandial glucose was $<180 \mathrm{mg} / \mathrm{dL}$ $(64.5 \%)$

About $84 \%$ of panelists chose a diabetes-specific polymeric, hypercaloric and high-protein composition for patients with diabetes/ hyperglycemia and COVID-19, and they opined that this formula can achieve an adequate glycemic control

Most of the panelists (70.4\%) stated that they initiate the enteral nutritional support when the patient cannot ingest $50 \%$ of the hospital diet or nutritional supplementation for more than $48 \mathrm{~h}$

There was a generalized agreement with these statements:

- NJT in case of high risk of aspiration, $79.5 \%$;

- NJT in case of limited gastric tolerance despite using prokinetic drugs, $81.8 \%$;

- Use of gastrostomy when indicated, $92.0 \%$

$51 \%$ of the panelists indicated that they used formulas for tube feeding with the same characteristics as the oral nutrition supplements; $49 \%$ of them used specific formulas for enteral tube feeding; 93\% initiates tube feeding with low-dose feeds; $67.0 \%$ used peristaltic pumps

Responses of the panelists were: Days 1-2: start feed at $20 \mathrm{~mL} / \mathrm{h}$ to test tolerance and increase the speed every $6-12 \mathrm{~h}$ to try to achieve $50 \%$ of patients' nutritional requirements within the first $24-48 \mathrm{~h}(71.9 \%)$; Days 3-7: increase progressively, assessing digestive tolerance, to $20-25 \mathrm{kcal} / \mathrm{kg} / \mathrm{day}(55 \%)$; From day 7 , escalate to $30 \mathrm{kcal} / \mathrm{kg} /$ day $(63.3 \%)$

$P C R$ polymerase chain reaction

\section{Discussion}

The medical community faces an unprecedented pandemic context in which patients' conditions are diverse and, on many occasions, complicated by comorbidities. Evidence shows that comorbidities, including diabetes, complicate the prognosis of people with COVID-19 [29], and their management poses a relevant clinical challenge. Thus, in this work 18 experts reviewed the evidence, discussed and generated consensus recommendations for the nutritional management of COVID-19 patients with diabetes/hyperglycemia during their hospitalization and after their discharge, and this consensus was contrasted with the usual clinical practice of health professionals (panelists) throughout Spain. A peculiarity of people with diabetes is that they often have a series of risk factors for malnutrition inherent to their disease. In addition to other comorbid conditions and polypharmacy, these patients may suffer from changes in appetite, limited mobility, social isolation, and depression, which contribute to a poor nutritional status and increase the prevalence of malnutrition in this population [30]. In fact, as reported by the panelists, the prevalence of malnutrition in patients 
Table 4 Comparative of the optimal care according to the experts' recommendations and the usual clinical practice of the panelists regarding malnutrition reevaluation and monitoring

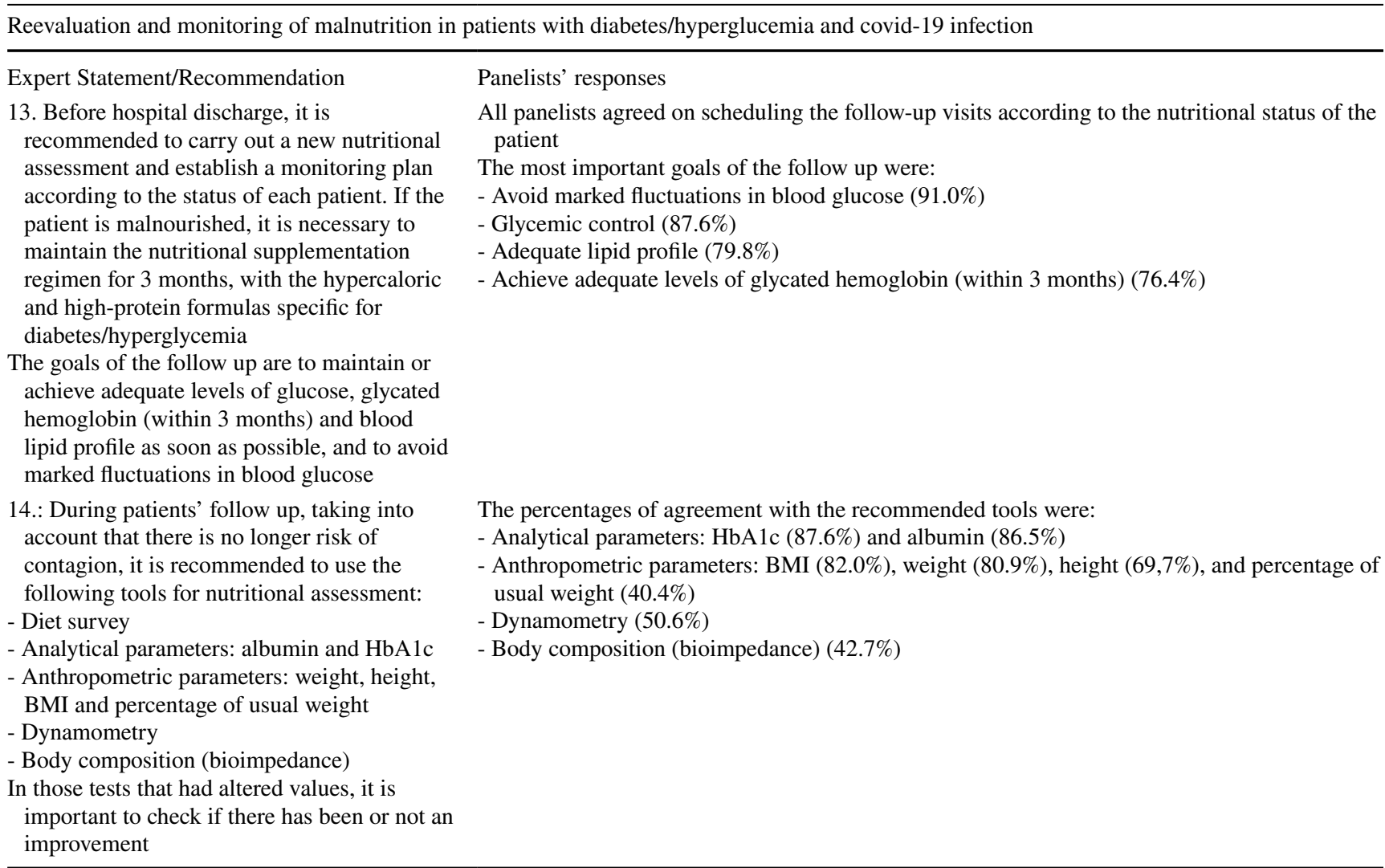

with diabetes and COVID-19 was 50\%. Importantly, many people with type 2 diabetes are overweight or obese, which can mask the suspicion of malnutrition [31]. However, when asked about this condition, all the panelists were aware that obese patients can actually suffer from malnutrition. Moreover, high BMI has been shown to be significantly associated with critical illness in patients with COVID-19 [32], being the excess adipose tissue the most probable link between obesity and COVID-19 severity [33]. These findings support that those inpatients with abdominal obesity should be monitored even more carefully.

An early determination of the nutritional status is essential to rapidly implement the correct dietetic and supplementary measures, necessary to fight DRM. The experts recommended the MUST [24] and the R-MAPP [25], both tools for malnutrition screening. The R-MAPP serves to remotely screen for malnutrition and sarcopenia, respectively, in a telemedicine setting, but can be useful when no direct contact with the patient is feasible (patient isolation, containment measures). On their part, the panelists preferred a more classical tool, the Mini Nutritional Assessment (MNA)-short form, that examines possible decreases in food intake, weight loss, psychological stress or acute disease during the past three months, and current mobility, and current BMI
[34]. The nutritional assessment should be done, and this was the common practice according to the panelists, at the same time of screening. The assessment mainly relies on the analytical parameters, anthropometrics, and diet survey, although dynamometry and bioimpedance can also be useful $[35,36]$. The practical guidance released by the European Society of Parenteral and Enteral Nutrition (ESPEN) recommends the use of GLIM criteria for diagnosing malnutrition in COVID-19 patients [37]. All these nutritional evaluations are time-consuming and required trained personnel to be available, but in the event of hospital collapse/high demand for hospitalization, a number of patients may not be evaluated. If the screening and/or nutritional assessment cannot be carried out, and given that patients with diabetes/ hyperglycemia and COVID-19 have high probabilities of presenting or developing malnutrition during hospitalization, assuming malnutrition may be an appropriate approach [38]. Even more, it may be advisable to screen and monitor glycemic and nutritional status during the routine evaluation of all COVID-19 patients, as elevated blood glucose levels predicted worse outcomes in hospitalized patients [39].

Sufficient provision of energy and protein is essential for improving clinical outcomes [40]. The energy and protein requirements for hospitalized COVID-19 patients with 
diabetes/hyperglycemia are based on the ESPEN recommendations [37], and most the panelists agreed on these estimations. However, protein requirements for patients with renal failure were deemed insufficient by the panelists, possibly because an update of the ESPEN recommendations [41] was published on the time interval between the experts' consensus and the panelist survey. These guidelines stated that, in hospitalized patient with acute kidney insufficiency and/or chronic kidney disease with acute/critical illness, not on renal replacement therapy, we should start with $1 \mathrm{~g} /$ $\mathrm{kg}$ body weight/day, and gradually increase up to $1.3 \mathrm{~g} / \mathrm{kg}$ body weight/day if tolerated. Patients on renal replacement therapy require higher protein intakes $(1.3-1.5 \mathrm{~g} / \mathrm{kg} / \mathrm{d})$ [41].

Inpatients with SARS-CoV-2 infection deal with particular barriers for a correct intake, due to the need for isolation. This means that they cannot count on external help (for example, a family member) during hospitalization, which can further increase the risk of malnutrition. Therefore, it is essential that the patients are aware of the relevance of a good diet/nutrition to accelerate their recovery and to provide them an adapted and enriched diet to favor intake [42]. An important goal is to achieve or maintain adequate glycemic levels, as recommends the American Diabetes Association [28]. Oral nutritional supplements could be prescribed to meet patient's needs, being the best option a diabetesspecific polymeric, hypercaloric and high-protein formula according to the experts' and panelists' opinions. These supplements were deemed appropriate to maintain an adequate glycemic control. Apart from covering energy and protein requirements, there are other components of the diet that may play a relevant role in COVID-19 severity. This is the case of vitamin $\mathrm{D}$, which has shown an association between its deficiency and severity/mortality of COVID-19 [43, 44], highlighting the need for avoiding hypovitaminosis $\mathrm{D}$. When oral intake is not possible, NGT or NJT tubes can be inserted for enteral nutrition, depending on the presence of diabetic gastroparesis or limited gastric tolerance; gastrostomy is indicated when prolonged enteral nutrition is expected [45].

It has been shown that COVID-19 patients who lose more than $10 \%$ of their habitual weight during their hospital stay or are admitted to an ICU present a high nutritional risk during follow-up [46]. The group of experts and the panelists agreed on the necessity of a new nutritional assessment before hospital discharge and to maintain the diabetesspecific oral supplements if patients are still malnourished. An important goal during nutritional monitoring is to avoid marked fluctuations in blood glucose, which can be exacerbated by COVID-19 [47], although the glycemic control and achieving a good lipid profile are also important.

In conclusion, the recommendations proposed by this expert group are intended to provide a useful guide on the clinical management of malnutrition in patients with COVID-19 and diabetes/hyperglycemia, in order to improve their outcomes and accelerate as much as possible their recovery. The comparison of the recommended optimal care with routine clinical practice makes it possible to identify gaps in knowledge, implementation difficulties, and areas for improvement in the management of malnutrition in this population.

Abbreviations COVID-19: Coronavirus disease 2019; SARS-CoV-2 : Severe acute respiratory syndrome coronavirus 2; DRM: Disease-related malnutrition; MUST: Malnutrition Universal Screening Tool; GLIM : Global Leadership Initiative on Malnutrition; CRP: C-reactive protein; MNA: Mini Nutritional Assessment; SARF-C: Strength, assistance with walking, rising from a chair, climbing stairs, and falls; BMI: Body mass index; BW: Body weight; EPA: Eicosapentaenoic acid; DHA: Docosahexaenoic acid; NGT: Nasogastric tube; NJT: Nasojejunal tube; PCR: Polymerase chain reaction; HbA1c: Hemoglobin A1c; R-MAPP: Remote Malnutrition APP; ESPEN: European Society of Parenteral and Enteral Nutrition; CGM: Continuous glucose monitoring

Funding This study was funded by Abbott.

Abbott Nutrition was the sponsor of the study, but it didn't participate in the design, research, data collection and data review.

\section{Declarations}

Conflicts of interest Authors have received speaker's fees and has worked on research projects of Abbott Nutrition, Fresenius-Kabi, Nestlé, and Nutricia.

Open Access This article is licensed under a Creative Commons Attribution 4.0 International License, which permits use, sharing, adaptation, distribution and reproduction in any medium or format, as long as you give appropriate credit to the original author(s) and the source, provide a link to the Creative Commons licence, and indicate if changes were made. The images or other third party material in this article are included in the article's Creative Commons licence, unless indicated otherwise in a credit line to the material. If material is not included in the article's Creative Commons licence and your intended use is not permitted by statutory regulation or exceeds the permitted use, you will need to obtain permission directly from the copyright holder. To view a copy of this licence, visit http://creativecommons.org/licenses/by/4.0/.

\section{References}

1. Thakur B, Dubey P, Benitez J, Torres JP, Reddy S, Shokar N, et al. A systematic review and meta-analysis of geographic differences in comorbidities and associated severity and mortality among individuals with COVID-19. Sci Rep. 2021;11:8562.

2. Bravata DM, Perkins AJ, Myers LJ, Arling G, Zhang Y, Zillich $\mathrm{AJ}$, et al. Association of intensive care unit patient load and demand with mortality rates in US Department of Veterans Affairs Hospitals during the COVID-19 pandemic. JAMA Netw Open. 2021;4:e2034266.

3. Huang C, Wang Y, Li X, Ren L, Zhao J, Hu Y, et al. Clinical features of patients infected with 2019 novel coronavirus in Wuhan. China Lancet. 2020;395:497-506.

4. Argenziano MG, Bruce SL, Slater CL, Tiao JR, Baldwin MR, Barr RG, et al. Characterization and clinical course of 1000 patients with coronavirus disease 2019 in New York: Retrospective case series. BMJ. 2020;369:m1996. 
5. Giacomelli A, Pezzati L, Conti F, Bernacchia D, Siano M, Oreni $\mathrm{L}$, et al. Self-reported olfactory and taste disorders in patients with severe acute respiratory coronavirus 2 infection: A cross-sectional study. Clin. Infect. Dis. 2020;889-90.

6. Casas-Rojo JM, Antón-Santos JM, Millán-Núñez-Cortés J, Lumbreras-Bermejo C, Ramos-Rincón JM, Roy-Vallejo E, et al. Clinical characteristics of patients hospitalized with COVID-19 in Spain: Results from the SEMI-COVID-19 Registry. Rev Clin Esp. 2020;220:480-94.

7. Mehta AA, Haridas N, Belgundi P, Jose WM. A systematic review of clinical and laboratory parameters associated with increased severity among COVID-19 patients. Diabetes Metab Syndr. 2021;15:535-41.

8. Wu C-T, Lidsky PV, Xiao Y, Lee IT, Cheng R, Nakayama T, et al. SARS-CoV-2 infects human pancreatic $\beta$ cells and elicits $\beta$ cell impairment. Cell Metab. 2021;33:1565-1576.e5.

9. Singh AK, Gillies CL, Singh R, Singh A, Chudasama Y, Coles $\mathrm{B}$, et al. Prevalence of co-morbidities and their association with mortality in patients with COVID-19: A systematic review and meta-analysis. Diabetes Obes Metab. 2020;22:1915-24.

10. Roncon L, Zuin M, Rigatelli G, Zuliani G. Diabetic patients with COVID-19 infection are at higher risk of ICU admission and poor short-term outcome. J Clin Virol. 2020;127:104354.

11. Corona G, Pizzocaro A, Vena W, Rastrelli G, Semeraro F, Isidori $\mathrm{AM}$, et al. Diabetes is most important cause for mortality in COVID19 hospitalized patients: Systematic review and meta-analysis. Rev Endocr Metab Disor. 2021;22:275-96.

12. Apicella M, Campopiano MC, Mantuano M, Mazoni L, Coppelli A, Del Prato S. COVID-19 in people with diabetes: understanding the reasons for worse outcomes. Lancet Diabetes Endocrinol. 2020;8:782-92.

13. Whyte MB, Vas P, Heiss C, Feher MD. The contribution of diabetic micro-angiopathy to adverse outcomes in COVID-19. Diabetes Res Clin Pract. 2020;164:108217.

14. Sardu C, D’Onofrio N, Balestrieri ML, Barbieri M, Rizzo MR, Messina $\mathrm{V}$, et al. Outcomes in patients with hyperglycemia affected by COVID-19: Can we do more on glycemic control? Diabetes Care. 2020;43:1408-15.

15. Kapoor R, Timsina LR, Gupta N, Kaur H, Vidger AJ, Pollander $\mathrm{AM}$, et al. Maintaining blood glucose levels in range (70-150 mg/ $\mathrm{dL}$ ) is difficult in COVID-19 compared to non-COVID-19 ICU patients-a retrospective analysis. J Clin Med. 2020;9.

16. Tappenden KA, Quatrara B, Parkhurst ML, Malone AM, Fanjiang G, Ziegler TR. Critical role of nutrition in improving quality of care: An interdisciplinary call to action to address adult hospital malnutrition. J Acad Nutr Diet. 2013;113:1219-37.

17. Burgos R, Joaquín C, Blay C, Vaqué C. Disease-related malnutrition in hospitalized chronic patients with complex needs. Clin Nutr. 2020;39:1447-53.

18. Bedock D, Bel Lassen P, Mathian A, Moreau P, Couffignal J, Ciangura C, et al. Prevalence and severity of malnutrition in hospitalized COVID-19 patients. Clin Nutr ESPEN. 2020;40:214-9.

19. Moore JB, June CH. Cytokine release syndrome in severe COVID19. Science. 2020;368:473-4.

20. Rouget A, Vardon-Bounes F, Lorber P, Vavasseur A, Marion O, Marcheix B, et al. Prevalence of malnutrition in coronavirus disease 19: The NUTRICOV study. Br J Nutr. 2020;1-8.

21. Zhu L, She Z-G, Cheng X, Qin J-J, Zhang X-J, Cai J, et al. Association of blood glucose control and outcomes in patients with COVID-19 and pre-existing type 2 diabetes. Cell Metab. 2020;31:1068-1077.e3.

22. Tastle WJ, Wierman MJ. Consensus and dissention: A measure of ordinal dispersion. Int J Approx Reason. 2007;45:531-45.
23. Carriel J, Muñoz-Jaramillo R, Bolaños-Ladinez O, Heredia-Villacreses F, Menéndez-Sanchón J, Martin-Delgado J, et al. CURB-65 as a predictor of 30-day mortality in patients hospitalized with COVID-19 in Ecuador: COVID-EC Study. Rev Clin Esp. 2020. https://doi.org/10. 1016/j.rce.2020.10.001.

24. Elia M. The MUST report: nutritional screening of adults: A multidisciplinary responsibility. 2003 https://www.bapen.org.uk/pdfs/ must/must-report.pdf. Accessed 4 Feb 2021.

25. Krznarić Ž, Bender DV, Laviano A, Cuerda C, Landi F, Monteiro $\mathrm{R}$, et al. A simple remote nutritional screening tool and practical guidance for nutritional care in primary practice during the COVID-19 pandemic. Clin Nutr. 2020;39:1983-7.

26. Malmstrom TK, Miller DK, Simonsick EM, Ferrucci L, Morley JE. SARC-F: a symptom score to predict persons with sarcopenia at risk for poor functional outcomes. J Cachexia Sarcopenia Muscle. 2016;7:28-36.

27. Hicks C, Trickett A, Kwan YL, Ramanathan S. The use of adjusted ideal body weight for overweight patients undergoing HPC mobilisation for autologous transplantation. Ann Hematol. 2012;91:1795-801.

28. American Diabetes Association Professional Practice Committee. 16. Diabetes care in the hospital: Standards of medical care in diabetes-2022. Diabetes Care. 2022;45:S244-53.

29. Liu H, Chen S, Liu M, Nie H, Lu H. Comorbid chronic diseases are strongly correlated with disease severity among COVID-19 patients: A systematic review and meta-analysis. Aging Dis. 2020;11:668-78.

30. Sanz París A, García JM, Gómez-Candela C, Burgos R, Martín Á, Matía P. Malnutrition prevalence in hospitalized elderly diabetic patients. Nutr Hosp. 2013;28:592-9.

31. Barazzoni R, Gortan CG. Double burden of malnutrition in persons with obesity. Rev Endocr Metab Disord. 2020;21:307-13.

32. Petrilli CM, Jones SA, Yang J, Rajagopalan H, O'Donnell L, Chernyak $\mathrm{Y}$, et al. Factors associated with hospital admission and critical illness among 5279 people with coronavirus disease 2019 in New York City: Prospective cohort study. BMJ. 2020;369:m1966.

33. Yang Y, Ding L, Zou X, Shen Y, Hu D, Hu X, et al. Visceral adiposity and high intramuscular fat deposition independently predict critical illness in patients with SARS-CoV-2. Obesity. 2020;28:2040-8.

34. Kaiser MJ, Bauer JM, Ramsch C, Uter W, Guigoz Y, Cederholm $\mathrm{T}$, et al. Validation of the Mini Nutritional Assessment short-form (MNA®-SF): A practical tool for identification of nutritional status. J Nutr Heal Aging. 2009;13:782.

35. Flood A, Chung A, Parker H, Kearns V, O'Sullivan TA. The use of hand grip strength as a predictor of nutrition status in hospital patients. Clin Nutr. 2014;33:106-14.

36. Slee A, Birch D, Stokoe D. A comparison of the malnutrition screening tools, MUST, MNA and bioelectrical impedance assessment in frail older hospital patients. Clin Nutr. 2015;34:296-301.

37. Barazzoni R, Bischoff SC, Breda J, Wickramasinghe K, Krznaric Z, Nitzan D, et al. ESPEN expert statements and practical guidance for nutritional management of individuals with SARS-CoV-2 infection. Clin Nutr. 2020;39:1631-8.

38. Caccialanza R, Laviano A, Lobascio F, Montagna E, Bruno R, Ludovisi $\mathrm{S}$, et al. Early nutritional supplementation in non-critically ill patients hospitalized for the 2019 novel coronavirus disease (COVID-19): Rationale and feasibility of a shared pragmatic protocol. Nutrition. 2020;74:110835.

39. Wang W, Chai Z, Cooper ME, Zimmet PZ, Guo H, Ding J, et al. High fasting blood glucose level with unknown prior history of diabetes is associated with high risk of severe adverse COVID-19 outcome. Front Endocrinol. 2021;12:791476. 
40. Silvah JH, de Lima CMM, Nicoletti CF, Barbosa AC, Junqueira GP, da Cunha SF de C, et al. Protein provision and lower mortality in critically ill patients with COVID-19. Clin Nutr ESPEN. 2021;45:507-10.

41. Fiaccadori E, Sabatino A, Barazzoni R, Carrero JJ, Cupisti A, De Waele E, et al. ESPEN guideline on clinical nutrition in hospitalized patients with acute or chronic kidney disease. Clin Nutr. 2021;40:1644-68.

42. Skrajnowska D, Brumer M, Kankowska S, Matysek M, Miazio N, Bobrowska-Korczak B. Covid 19: Diet composition and health. Nutrients. 2021;13.

43. Radujkovic A, Hippchen T, Tiwari-Heckler S, Dreher S, Boxberger M, Merle U. Vitamin D deficiency and outcome of COVID-19 patients. Nutrients. 2020;12.

44. Chiodini I, Gatti D, Soranna D, Merlotti D, Mingiano C, Fassio A, et al. Vitamin D status and SARS-CoV-2 infection and COVID19 clinical outcomes. Front Public Heal. 2021;9:736665.
45. Goyal H, Ali A, Bansal P. Percutaneous endoscopic gastrostomy tube placement in COVID-19 patients. Front Nutr. 2021;8:603276.

46. Fiorindi C, Campani F, Rasero L, Campani C, Livi L, Giovannoni $\mathrm{L}$, et al. Prevalence of nutritional risk and malnutrition during and after hospitalization for COVID-19 infection: Preliminary results of a single-centre experience. Clin Nutr ESPEN. 2021;45:351-5.

47. Shen Y, Zhang L, Fan X, Zhou J. Glycemic fluctuations caused by COVID-19: Results from continuous glucose monitoring. Obes Med. 2021;22:100328.

Publisher's Note Springer Nature remains neutral with regard to jurisdictional claims in published maps and institutional affiliations. 